\title{
SLEEP HABITS OF HEALTHY YOUNG ADULTS: USE OF A SLEEP QUESTIONNAIRE
}

\author{
M. W. JOHNS, T. J. A. GAY, M. D. E. GOODYEAR, AND J. P. MASTERTON \\ Department of Surgery, Monash University, Melbourne, Australia
}

The pattern of sleep and wakefulness varies widely between individual people and is influenced by many factors. Several reports involving subjective recording of sleep habits in young adults have been published, with particular emphasis on the duration of sleep (Bousfield, 1940; Lawrence and Shurley, 1970; Webb and Agnew, 1970). However, the variations within such a population and relationships between the various aspects of behaviour relating to sleep and wakefulness have not been described adequately. Much of the emphasis in the many sleep laboratories which have been established throughout the world has been on all-night electroencephalogram monitoring. Details of the usual pattern of dreaming and non-dreaming sleep stages have been described for normal people of different ages and for patients with various physical and psychiatric illnesses (Kales, 1969). Important as such methods are in providing basic information on the nature of sleep and dreams, they do not tell us all we want to know about people's usual pattern of sleep and wakefulness and the factors which influence this pattern. For instance, electronic methods used in the laboratory do not tell us at what time our experimental subject usually goes to bed and to sleep at night when he is at home, nor do they tell us how often he dozes during the day, how often he takes sleeping tablets, how he feels about the quality of his sleep, and so on. This information can be obtained by means of detailed subjective reports in the form of either daily sleep charts kept for several weeks or a sleep questionnaire. Such methods of subjective reporting have been used among various occupational groups as well as hospital patients and healthy people of different ages (Lewis and Masterton, 1957; Masterton, 1965 a, b; McGhie and Russell, 1962; Johns, Egan, Gay, and Masterton, 1970). The importance of both subjective and objective methods for describing sleep habits in detail has recently been emphasized (Johns, 1971).

The accuracy of subjective estimates of such parameters as the usual delay to sleep onset and the duration of sleep has been measured using objective techniques in the laboratory (Lewis, 1969; Baekeland and Hoy, 1970). There is a significant correlation between these subjective and objective measures, $\vec{\circ}$ but the former tend to over-estimate the delay to $\overrightarrow{\vec{H}}$ sleep onset and to under-estimate the duration of $\stackrel{\sigma}{\sigma}$ sleep. This is a definite disadvantage in using sleep $\frac{\vec{D}}{2}$ questionnaires but does not preclude their use, especi- ? ally in determining the relationships between sleep of habits in different groups of people. Monroe (1967) $\rightarrow$ studied groups of 'good' and 'poor' sleepers who were healthy young adults selected on the basis of their responses to a sleep questionnaire. The 'poor' sleepers reported usually having longer delays and more difficulty in falling asleep, and they woke up more often during the night than 'good' sleepers. The two groups did in fact have objective differences in the duration of their sleep, number of night awakenings, and the pattern of sleep stages whes monitored electronically. Similar studies have. demonstrated significant objective differences in the sleep patterns of subjects reporting to be 'long' as opposed to 'short' sleepers (Hartmann, Baekeland, Zwilling and Hoy, 1970; Webb and Friel, 1971).

In the present study a sleep questionnaire was given to a relatively homogeneous population of $\triangle$ fourth-year medical students at Monash University, $\overrightarrow{0}$ Melbourne in 1969 and 1970. This involved 249 students, all of whom were of similar age and daily routine. In this report we shall describe the variations in, and the intercorrelations between, the answers given by these students to questions relating to the quality and quantity of their usual sleep. Some of these students took part also in two additional studies of the relationship between levels of adrenocortical activity and sleep habits, and between personality and sleep habits, the results of which will be reported separately. This study forms part of a $\frac{D}{O}$ long-term investigation of normal variations in subjectively reported sleep and the nature of in- No somnia which is such a common symptom among hospital patients and in the general community 0 (Johns et al., 1970).

\section{STUDENTS}

\section{METHOD}

Sleep questionnaires were completed by $122 \stackrel{\mathscr{P}}{+}$ students in 1969 and by 127 in 1970, the total of 
249 being $87 \%$ of a possible 286 students enrolled. The groups included all those assembled at a teaching session for fourth-year medical students in August 1969, at the end of the winter, and in March 1970 , one month after the end of the summer vacation. Their ages at the time were all very similar, $21.5 \pm 1.5$ years, as were their daily routines in the first year of clinical studies during which there were no professional examinations. There were 213 men and 26 women; 230 were unmarried, 17 were married, and 2 were divorced or separated.

\section{Sleep Questionnaire}

A questionnaire was desgined which asked such questions as 'at what time do you usually go to bed at night on weekdays?', and 'how would you describe your usual sleep?'. A range of possible answers was provided and the most appropriate were selected by each student. The questionnaire used in 1970 had 27 questions while that in 1969 had 31 questions, all of the important questions being the same. The total delay before falling asleep, duration of night awakenings and of sleep during the night and day, etc., were each calculated in hours per week rather than hours per 24 hours, thereby partially overcoming differences between weekdays and weekends which have been described elsewhere for hospital patients (Johns et al., 1970) and which have been reported here also. The answers to questions relating to the frequency of recall of nightmares and difficulty in getting off to sleep were recorded only as 'frequently', 'occasionally' or 'very seldom'. The answers to most of the questions were entered into a data file on magnetic tape and processed by a CDC 3200 computer using Fortran programmes written by the authors. The statistical significance of differences between the means of normally distributed variables was assessed by means of two-tailed Student's $t$ tests and between other frequency distributions by chi-squared tests. Product-moment correlation coefficients were computed to form an intercorrelation matrix involving 11 of the variables.

\section{RESULTS}

\section{Times of Falling Asleep and Waking UP}

The results are summarized in Table I. The mean time of going to bed on weeknights was about $\mathbf{1 1 . 3 0}$ p.m. but was 1 hour 20 minutes later at weekends (Friday and Saturday nights). In each year the distribution of answers to these questions was very similar, being approximately normally distributed with a slight degree of negative skewness. The students reported going out and hence going to bed significantly later than usual on an average of 1.9 nights per week, usually involving Friday and
TABLE I

TIMES OF GOING TO BED AT NIGHT AND WAKING UP IN THE MORNING

\begin{tabular}{|c|c|c|c|}
\hline & $\begin{array}{l}\text { Mean } \\
\text { Time } \\
\text { (hr) }\end{array}$ & $\begin{array}{l}\text { S.D. } \\
\text { (min.) }\end{array}$ & $\begin{array}{c}\text { Statistical } \\
\text { Significance } \\
\text { of Difierences }\end{array}$ \\
\hline $\begin{array}{l}\text { (a) Time of going to bed on } \\
\text { weeknights, } 1969 \text { and } \\
1970 \text { students } \\
\text { (b) Time of going to bed at } \\
\text { weekends, } 1969 \text { and } 1970 \\
\text { students } \\
\text { (c) Time of waking up in } \\
\text { morning on week-days, } \\
1969 \text { students, winter } \\
\text { (d) Time of waking up in } \\
\text { morning at week-ends, } \\
1969 \text { students, winter } \\
\text { (e) Time of waking up in } \\
\text { morning on week-days, } \\
1970 \text { students, summer } \\
\text { (f) Time of waking up in } \\
\text { morning at week-ends, } \\
1970 \text { students, summer }\end{array}$ & $\begin{array}{l}2325 \\
0045 \\
0723 \\
0918 \\
0655 \\
0842\end{array}$ & $\begin{array}{l}45 \\
65 \\
30 \\
75 \\
32 \\
71\end{array}$ & $\begin{array}{l}\text { (c) }-(d) \mathrm{P}<0.001 \\
\text { (c) }-(e) \mathrm{P}<0.001 \\
(\text { e })-(f) \mathrm{P}<0.001 \\
(d)-(f) \mathrm{P}<0.001\end{array}$ \\
\hline
\end{tabular}

Saturday nights. The mean times for waking up in the morning were much later on weekends than on weekdays. Unlike the times of going to bed, there was a statistically significant difference between the mean times of waking up in the morning both on weekdays and at weekends for the students in each year.

The majority of students took less than 15 minutes to fall asleep on weeknights and a few minutes less again at weekends $(P<0.05)$. However, about $10 \%$ took more than half an hour to fall asleep on weeknights and 5\% took as long on weekends. Most subjects finally got out of bed less than 15 minutes after waking up on weekdays but spent about three times as long lying in bed after waking up on weekends $(P<0.001)$. The students in both years gave similar answers to these questions also.

\section{Night AwakenINGS}

The majority of students $(62.7 \%)$ did not usually wake up during the night or woke up less than once per week. However, about $12 \%$ usually woke up on at least four nights per week, some more than once each night. The mean total duration of night awakening was 15 minutes per week, and $6 \%$ reported more than a total of 1 hour awake during the night each week. The commonest reasons given for waking up during the night were spontaneous awakening, need to pass urine, noise, nervous tension, and dreams or nightmares.

\section{Duration of SLeep}

The mean total duration of night sleep ( \pm S.D.) calculated for students in 1969 was $55.1 \pm 4.3$ hours per week, whereas in 1970 it was $51.1 \pm 5.7$ hours per_week, a difference of 4 hours which was very 
highly significant $(P<0.001)$. The only other significant differences between these groups were their time of morning awakening and total times spent in bed. They went to bed at the same time, had similar delays before falling asleep and before getting up in the morning, and similar duration of night awakenings. It seems likely, therefore, that the differences in sleep durations reflect the different times of the year when they were reported. The 1969 students were reporting sleep habits of the winter months, whereas the 1970 students' reports referred to the summer months. This suggests that half an hour less sleep is obtained each night during the summer as a result of waking up earlier and spending half an hour less time in bed each night, while keeping other aspects of sleep habits similar to those in winter. Regardless of this difference, an average of $92 \%$ of the total time in bed was spent asleep and $8 \%$ awake in both cases. The total time lying in bed awake at night amounted to $4.3 \pm 2.3$ hours per week.

The durations of sleep at night on weekdays and weekends were calculated separately for each of the 122 students in 1969. They reported getting a mean of 7.7 hours of sleep per night on weeknights and 8.4 hours per night on each of the Friday and Saturday nights, a highly significant difference ( $P<0.001)$. Therefore, although they went to bed later on weekends than weekdays, they also woke up next morning much later than on weekdays; consequently their mean duration of sleep was increased at weekends. Those students who obtained more than average amount of sleep on weekdays obtained less than average amount on weekends, and vice versa. There was, therefore, a highly significant negative correlation between the duration of weeknight sleep and the change in amount of sleep from weeknights to weekends in each student $(r=-0.52, P<0.001)$. More than half of the students $(53 \%)$ reported obtaining some sleep during the day for an average week. The mean duration of day sleep in the whole group was about 40 minutes per week.

\section{Quality of Sleep}

In response to a question about the quality of their usual sleep, $60 \%$ of the students described it as 'very good', $35 \%$ as 'moderately good', $5 \%$ as 'moderately bad', and none described it as 'very bad'. The majority $(92.4 \%)$ 'never' took hypnotic 宁 drugs, $7 \cdot 2 \%$ 'occasionally' took them, but only $0.4 \%$ N (1 subject) took them 'frequently'. A majority of subjects said they had no recall of disturbing dreams i or nightmares in recent months, whereas $35 \%$ had 'occasional' and 3\% had 'frequent' episodes of this 을 type.

\section{Relationship between Sleep Parameters in INDIVIDUAL SUBJECTS}

The means and standard deviations presented

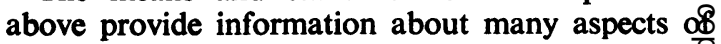
the overall pattern of sleep and wakefulness in the population of medical students. However, the presentation does not enable us to describe the relationship between the various aspects of sleep habits which may or may not be interrelated in individual subjects. Thus, product-moment correlation coefficients were calculated between the variables. The data for 104 students from the 1970 class were used for this purpose because the same calculations

TABLE II

INTERCORRELATIONS BETWEEN PARAMETERS OF SLEEP REPORTED BY MEDICAL STUDENTS

\begin{tabular}{|c|c|c|c|c|c|c|c|c|c|c|c|}
\hline & 1 & 2 & 3 & 4 & 5 & 6 & 7 & 8 & 9 & 10 & 11 \\
\hline 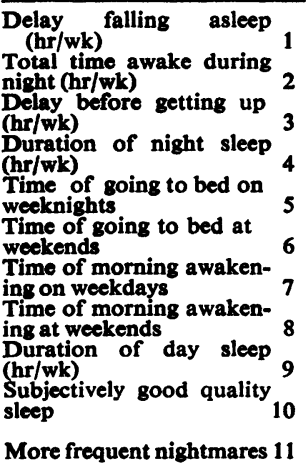 & $\begin{array}{c}1.00 \\
0.30 * \\
-0.07 \\
-0.23 \\
0.05 \\
-0.14 \\
0.15 \\
0.06 \\
0.18 \\
-0.42 \\
0.11\end{array}$ & $\begin{array}{c}1.00 \\
-0.04 \\
-0.34 \\
0.10 \\
0.12 \\
0.13 \\
-0.01 \\
0.29 \\
-0.22 \\
0.11\end{array}$ & $\begin{array}{c}1.00 \\
0.11 \\
-0.05 \\
-0.35 \\
-0.04 \\
-0.19 \\
-0.01 \\
0.07 \\
0.11\end{array}$ & $\begin{array}{c}1.00 \\
-0.55 \\
-0.33 \\
0.20 \\
0.19 \\
-0.31 \\
0.09 \\
-0.13\end{array}$ & $\begin{array}{c}1.00 \\
0.33^{*} \\
0.40 \\
0.23 \\
0.17 \\
-0.03 \\
0.08\end{array}$ & $\begin{array}{c}1.00 \\
0.05 \\
0.39 \\
0.11 \\
-0.03 \\
-0.06\end{array}$ & $\begin{array}{c}1.00 \\
0.36 \\
0.06 \\
-0.22 \\
-0.08\end{array}$ & $\begin{array}{r}1.00 \\
0.06 \\
-0.18 \\
-0.04\end{array}$ & $\begin{array}{r}1.00 \\
-0.06 \\
0.02\end{array}$ & $\begin{array}{r}-1.00 \\
0.25\end{array}$ & 1.00 \\
\hline
\end{tabular}

$\because P<0.05 * P<0.01 \quad * 0 \times 0.001$ 
were required in a detailed study of sleep habits and personality involving the same sample of students.

From Table II it can be seen that many of the variables describing the usual pattern of sleep and wakefulness and quality of sleep were significantly intercorrelated. For instance, the time of going to bed on weeknights was highly correlated with the time of going to bed at weekends despite a mean difference of 1 hour 20 minutes between these times. Students who tended to go to bed earliest at night and wake up earliest in the morning on weekdays also did so at weekends. Later times of going to bed were associated with less sleep and later awakenings next morning. Long delays in falling asleep were associated with more time awake during the night, less night sleep overall, and a subjective feeling of poorer quality sleep. The longer the total duration of night awakenings the less sleep was obtained at night, but also the more daytime sleep was obtained, as if to compensate for loss of night sleep. Increased delay before getting out of bed in the morning was related to early times of going to bed at night and earlier morning awakening at weekends but not on weekdays. Subjectively good quality sleep was associated with reports of rapid onset of sleep, few and brief night awakenings, early morning awakening, and the absence of nightmares or disturbing dreams. This early morning awakening must be that associated with early times of going to bed and restful sleep rather than the very early morning awakening which is a distressing symptom, especially in patients suffering from depression. The recall of disturbing dreams or nightmares was associated with subjectively poorer quality sleep but not with significant changes in the times or duration of sleep.

\section{Discussion}

The duration of night sleep calculated from the questionnaire responses of these medical students is in keeping with several other studies of young adults. Bousfield (1940) reported a mean duration of sleep of 7.36 hours per night ( 51.6 hours per week) in 532 undergraduate psychology students in the United States of America. Webb and Agnew (1970) reported that $79 \%$ of 2,369 17-year-old students entering the University of Florida obtained between 7 and 8 hours' sleep at night. Tune (1969) reported a mean of 7.7 hours per night (53.9 hours per week) for the sleep of healthy men 20 to 29 years old.

The difference in young adults between sleep on weeknights and weekends which we have reported here and elsewhere (Johns et al., 1970) does not seem to have been investigated by others. The consistency of these differences makes it difficult to limit any discussion about the duration of sleep only to a 24-hour period as is often attempted. It is suggested that a week usually includes a cycle of sleep-wakefulness behaviour which is fairly characteristic of each subject. Therefore, a week should be the minimum period considered in any discussion of the characteristics of this behaviour. Young adults tend to go to bed later on Friday and Saturday nights and sometimes other nights of the week but, in the absence of demands for early rising in the morning at weekends, tend to sleep later than on weekdays. Our finding that students probably sleep less during the summer than the winter months, likewise, does not appear to have been reported by others. By contrast, Masterton (1965b) showed by means of daily reports of sleep duration for eight weeks in medical students that, on the average, more sleep was obtained on holidays than during the university term.

What has been demonstrated in the present study is that, even in a population of young adults which is relatively homogeneous with respect to age and daily routine, there are considerable variations in the reported patterns of sleep and wakefulness. Despite limitations in the accuracy of subjective reports of such parameters as the usual time of going to bed on week-nights, a definite pattern of correlations between these parameters has been found. This pattern is similar to that reported by male medical and surgical patients of similar age using the same sleep questionnaire (Johns et al., 1970) and by healthy adults using a sleep chart for several weeks (Tune, 1969).

Sleep disturbance is a poorly understood but very common symptom in our communities. There is no generally accepted definition or overall measure of the degree of sleep disturbance in different people. It is often stated that difficulty in getting off to sleep and frequent night awakenings are characteristic of people with anxiety neurosis, whereas early morning awakening is a specific sign of depression. While it does appear that these symptoms are more common in these respective diagnostic groups, most aspects of sleep disturbance appear in different individuals in almost every acute psychiatric condition (McGhie, 1966; Mendels and Hawkins, 1968; Kupfer, Wyatt, Scott, and Snyder, 1970). There is no clear division between normal and pathological in any of the parameters of the sleep-wakefulness pattern. In a 'healthy' population of medical students, such as we have studied, there are some people who report that they are unsatisfied with the way they usually sleep. It appears that between 5 and $10 \%$ of the student population have a long-term tendency to have minor to moderately severe sleep disturbances, depending on how seriously one views their complaints. These people tend to lie at the extremes on several para- 
meters, few of which by themselves are diagnostic of sleep disturbance. The behavioural aspects of the sleep-wakefulness pattern which characterized even their mildest degree of sleep disturbance were similar to those reported by severely disturbed sleepers, with one exception. The longest delays in falling asleep were associated generally with the most frequent and longest night awakenings, the shortest duration of night sleep, and the greatest amount of day sleep. But very early morning awakening and inability to go back to sleep were not features of sleep disturbance among the students, whereas they are common but not universal symptoms among psychiatric patients, especially those suffering from depression (McGhie, 1966).

The ability to remain awake during the day and to remain soundly asleep for several hours at night is influenced by many factors, both within the subjects and their environment. For example, we have found that several aspects of the sleep-wakefulness pattern in the medical students studied here were related to their psychological characteristics measured by the Minnesota Multiphasic Personality Inventory. We have also demonstrated in some of these students that differences in subjectively reported sleep habits are related to their mean rates of urinary corticosteroid excretion (Johns, Gay, Masterton and Bruce, 1971). Those students who were 'poor' sleepers (who woke up more often during the night, took longest to fall asleep, who reported getting poor quality sleep at night, and who dozed most during the day) had evidence of more chronic psychological distress and higher levels of adrenocortical activity than 'good' sleepers. The season of the year and other environmental factors, such as occupational and social demands made on junior hospital medical staff, also change the pattern of sleep and wakefulness, without necessarily leading to sleep disturbance (Masterton, 1965a). Few middle-aged or elderly people would be considered to have disturbed sleep if they usually slept as well as most young adults, perhaps taking $\mathbf{3 0}$ minutes to fall asleep and waking up once each night for a few minutes. Increasing age, therefore, is one of the most important factors associated with sleep disturbance (Tune, 1969; Johns et al., 1970).

While the accurate description of sleep characteristics in terms of sleep stages in individual subjects requires electronic monitoring methods, it is suggested that much information about sleep habits can be obtained from large numbers of people by the use of a detailed sleep questionnaire. This method can give an overall picture of a person's pattern of sleep and wakefulness throughout the week which could not be derived from electronic monitoring methods used only at night in a sleep laboratory. It seems that most people adopt a life pattern of sufficient constancy that they can estimate its characteristics subjectively in a meaningful way. The same parameters can be used to describe normal variations in sleep habits and the whole range of degrees of sleep disturbance.

\section{SUMMARY}

Several aspects of the usual pattern of behaviour relating to sleep and wakefulness among medical students were investigated by means of a detailed sleep questionnaire. The mean duration and times of sleeping were different from weekdays to weekends. Therefore, the total duration of sleep was calculated in hours per week rather than hours per 24 hours, and was similar to that of other young adults. More sleep was obtained in winter than in summer. Those who reported usually getting 'good' sleep reported the most rapid onset of sleep, fewest night awakenings, early morning awakening, and absence of nightmares. Between 5 and $10 \%$ of students had mild sleep disturbances characterized by the same parameters as those of more severe insomnia in psychiatric patients, except for very early morning awaken ing. Most people adopt a life pattern of sufficient constancy with regard to sleep and wakefulness that they can report its general characteristics in a mean ingful way in a sleep questionnaire. Some of the information thereby obtained cannot be provided by electronic monitoring methods in the laboratory.

The National Health and Medical Research Council of $\stackrel{D}{\varrho}$ Australia supported this work by way of a Medical Post- $\overrightarrow{\vec{A}}$ graduate Research Scholarship awarded to M.W.J. and Medical Research Scholarships awarded to T.J.A.G. and M.D.E.G.

\section{REFERENCES}

BaEkeland, F., and Hoy, P. (1970). Reported vs recorded sleep patterns. Paper read at Annual Conference, Association for Psychophysiological Study of Sleep, Santa Fe, March 1970.

BousfirLd, W. A. (1940). The relation of the euphoric attitude to the quality of sleep. J. Psychol., 9, 393.

HartmanN, E., BaEkeland, F. Zwilling, G., and HoY, P. (1970). Sleep need: How much and what kind? Paper presented to the 123rd Annual Meeting of the American Psychiatric Association, San Francisco, 1970. N

JoHNs, M. W. (1971). Methods for assessing human sleep. Arch. intern. Med., 127, 484.

, Egan, P., Gay, T. J. A., and Masterton, J. P. 心 (1970). Sleep habits and symptoms in male medical $O$ and surgical patients. Brit. med. J., 2, 509.

, GAY, T. J. A., MASTERTON, J. P., and BRUCE, D. W. (1971). Relationship between sleep habits, adreno- 足 cortical activity and personality. Psychosom. Med., in press. 
Kales, A. (Ed.) (1969). Sleep; Physiology and Pathology. Lippincott, Philadelphia.

KuPfer, D. J., Wyatt, R. J., ScotT, J., and SNyder, F. (1970). Sleep disturbance in acute schizophrenic patients. Amer. J. Psychiat., 126, 1213.

LAWrenCe, B. and Shurley, J. T. (1970). Napping habits of a college student population. Paper read at Annual Conference of Association for Psychophysiological Study of Sleep, Santa Fe, March 1970.

Lewis, H. E., and MAsterton, J. P., (1957). Sleep and wakefulness in the Arctic. Lancet, 1, 1262.

LEWIS, S. A. (1969). Subjective estimates of sleep: an EEG evaluation. Brit. J. Psychol., 60, 203.

Masterton, J. P. (1965a). Sleep of hospital medical staff. Lancet. 1, 41.

-_, (1965b). Patterns of sleep. In: The Physiology of Human Survival, edited by O. G. Edholm and A. L. Bacharach p. 387. Academic Press, London.
MCGHIE, A. (1966). The subjective assessment of sleep patterns in psychiatric illness. Brit. J. med. Psychol., 39, 221.

- and Russell, S. M. (1962). The subjective assessment of normal sleep patterns, J. ment. Sci., 108, 642.

Mendels, J., and Hawkins, D. R. (1968). Sleep and depression. Further considerations. Arch.gen. Psychiat., 19, 445.

Monroe, L. J. (1967). Psychological and physiological differences between good and poor sleepers. J. abnorm. Psychol., 72, 255.

TUNE, G. S. (1969). Sleep and wakefulness in 509 normal human adults. Brit. J. med. Psychol., 42, 75.

WEBB, W. B., and AGNEW, H. W., Jr., (1970). Sleep stage characteristics of long and short sleepers. Science, 168, 146.

- and FrIEL, J. (1971). Sleep stage and rersonality characteristics of "natural" long and short sleepers. Science, 171, 587. 